\title{
O Grace Memorial Hospital e a Missão Presbiteriana norte-americana no Brasil: fontes para a história da assistência à saúde, 1955-1971
}

\author{
Grace Memorial Hospital and the American Presbyterian \\ Mission in Brazil: sources for the history of healthcare, 1955-1971
}

\author{
Maria Elisa Lemos \\ Nunes da Silva ${ }^{i}$ \\ i Professora, graduação em História \\ e Programa de Pós-graduação em \\ História/Universidade do Estado \\ da Bahia. \\ Alagoinhas - BA - Brasil \\ orcid.org/0000-0002-4502-4730 \\ elisa.lemos@uol.com.br
}

\section{Ricardo dos Santos Batista ${ }^{i i}$ \\ ii Professor, Programa de Pós-graduação em História/ Universidade do Estado da Bahia. Alagoinhas - BA - Brasil orcid.org/0000-0002-7959-5929 kadobatista@hotmail.com}

Recebido em 26 jul. 2018. Aprovado em 10 jan. 2019.
SILVA, Maria Elisa Lemos Nunes da; BATISTA, Ricardo dos Santos. O Grace Memorial Hospital e a Missão Presbiteriana norte-americana no Brasil: fontes para a história da assistência à saúde, 1955-1971. História, Ciências, Saúde-Manguinhos, Rio de Janeiro, v.26, supl., dez. 2019, p.249-259.

\begin{abstract}
Resumo
Apresenta aspectos da história e do acervo documental do Grace Memorial Hospital, instituição criada em 1926 na antiga cidade de Ponte Nova, atual Wagner, na Chapada Diamantina (BA), pelo médico e missionário presbiteriano norte-americano Walter Welcome Wood. O corpus documental está sob guarda da Universidade do Estado da Bahia, campus II, Alagoinhas, desde o encerramento definitivo das atividades do hospital, e constitui-se em fonte de pesquisa para diferentes áreas de estudo, especialmente para a história da assistência à saúde no Brasil. Os documentos auxiliam as análises sobre a incidência de doenças, tratamentos médicos e outros cuidados com a saúde em uma população que não tinha acesso a outras instituições que atuassem nesse âmbito.

Palavras-chave: história da assistência; Missão Presbiteriana no Brasil; instituições hospitalares.
\end{abstract}

\begin{abstract}
The paper presents aspects of the history and archives of Grace Memorial Hospital, founded in 1926 in the former town of Ponte Nova, now Wagner, in the Chapada Diamantina region of Bahia state, Brazil, by the American Presbyterian missionary and doctor Walter Welcome Wood. The documents in question have been kept at the Universidade do Estado da Bahia, campus II, Alagoinhas, since the hospital closed down definitively. They constitute a source of research for different areas of scholarship, especially the history of healthcare in Brazil. The documents are used in analyses of the incidence of diseases, medical treatments, and other care given to a population that had no access to other institutions working in this area.
\end{abstract}

Keywords: history of healthcare; Presbyterian Mission in Brazil; hospitals. 
$\mathrm{E}$ ste artigo tem como objetivo apresentar aspectos da história e do acervo documental do Grace Memorial Hospital, instituição criada na antiga cidade de Ponte Nova, atual município de Wagner, localizado na Chapada Diamantina, a $390 \mathrm{~km}$ da cidade de Salvador (BA), como desdobramento da Missão Presbiteriana norte-americana no Brasil. O hospital surgiu em 1916, após a chegada do médico e missionário Walter Welcome Wood, enviado ao país para cuidar da saúde de professores e estudantes do Instituto Ponte Nova, uma estação missionária criada em 1906, voltada para a educação e para a evangelização.

Concluído no ano de 1925 e inaugurado oficialmente em 1926, o prédio principal recebeu o nome de Grace Memorial Hospital em homenagem a Grace Brown Wood, primeira esposa do médico, falecida em 1921 (Santos, 2017, p.174). Como outras instituições estrangeiras que desenvolveram atividades caritativas e/ou filantrópicas nas Américas na primeira metade do século XX, a exemplo da Fundação Rockefeller, os presbiterianos realizaram um projeto que visava à "civilização" da população residente nos sertões brasileiros. O hospital dos presbiterianos desempenhou papel fundamental na assistência à saúde em Wagner e em toda a Chapada Diamantina, funcionando, por muitos anos, como único estabelecimento dessa natureza na região.

A assistência pode ser compreendida como um conjunto diversificado de práticas que se inscrevem numa estrutura comum, determinada pela existência de categorias de populações carentes, assim como pela necessidade de atendê-las. Ela se manifestou de diferentes formas ao longo da história, com o objetivo de prestar auxílio aos que não possuíam condições de prover seu sustento (Castel, 2010, p.47). Em relação ao contexto brasileiro, é possível afirmar que,

até o início do século XX, assistência significava uma gama variada de ações que passavam pela parturiente, pela criança, pelo idoso e pelo doente. ... foi uma das formas de suavizar a pobreza. A princípio organizada pelas irmandades devocionais e/ou confrarias profissionais, caracterizou-se por uma solidariedade horizontal (entre iguais) e por separar o bom pobre do mau pobre - aquele[,] afeito ao trabalho (Sanglard, Ferreira, 2018, p.145).

No modelo liberal, adotado pelo Império brasileiro e previsto na Constituição republicana de 1891, cabiam à própria sociedade a sua organização e ao Estado a intervenção apenas em momentos de calamidades. Nesse arranjo de direito e deveres, a sociedade se organizava por meio das ações das irmandades, especialmente a da Misericórdia, e de sociedades de auxílio mútuo, enquanto o Estado criava e mantinha órgãos que regulavam e tratavam da higiene nos portos, mantinha os hospitais de isolamento e atuava em épocas de epidemias (Souza, Sanglard, 2011, p.28).

A Santa Casa de Misericórdia da Bahia, por sua vez, dependeu da caridade particular como fonte principal de rendimentos, embora tivesse uma finalidade semiburocrática na oferta dos serviços hospitalares, no auxílio aos presos e nos cuidados aos enjeitados, como um braço da Coroa portuguesa no ultramar. O Hospital da Misericórdia foi o único hospital geral da Bahia nos séculos XVII e XVIII que proporcionava assistência médica a todos, independentemente de cor, classe ou credo religioso (Russell-Wood, 1981, p.111, 130).

Maria Renilda Nery Barreto (2011, p.20) destaca que, desde o início da colonização até as primeiras décadas do século XX, a população residente nos sertões baianos poderia, em caso 
de doença, buscar auxílio nos hospitais mantidos pelas Santas Casas da Misericórdia existentes na capital e no interior do estado. Entre os séculos XVI e XIX, foram criadas as Santas Casas de Misericórdia de Belmonte (s.d.), Ilhéus (1564), Cachoeira (1826), Nazaré (1830), Feira de Santana (1859), Valença e Maragogipe (1860), Santo Amaro (1878), Juazeiro (1885) e Amargosa (1892) (Barreto, 2011, p.3). Do início do século XX até 1939, surgiram as de Itabuna, Vitória da Conquista, Alagoinhas, São Félix, Esplanada e Bonfim (Batista, 2017, p.210).

Algumas das Misericórdias da Bahia eram seculares e de grandes patrimônios, como as de Cachoeira, Maragogipe e Santo Amaro. Elas acumulavam imóveis sob sua posse, que provinham de doações de beneméritos e filantrópicos. Mesmo assim, em alguns momentos as instituições passavam por dificuldades, pois não tinham recursos para realizar as reformas necessárias e para manter e ampliar a assistência hospitalar. Batista (2018, p.55) afirma que o hospital de Cachoeira possuía mais de trinta prédios no início de 1919, mas apenas cinco pacientes internados. Em casos como esse, uma alternativa para a situação dos mais graves era encaminhá-los ao Hospital Santa Izabel, em Salvador.

Ao analisar a obra produzida por Francisco Vicente Vianna, encomendada pelo então governador da Bahia, Joaquim Manuel Rodrigues Lima, que descreveu hospitais, enfermarias, casas de saúde, asilos e cemitérios baianos na Primeira República, Souza e Sanglard (2011, p.34-41) mostram que o autor dividiu as instituições assistenciais em diferentes tipos. Vianna estabelecia uma hierarquia composta por "conventos", modo como classificava os hospícios; "hospitais, enfermarias, casas de saúde, asilos e cemitérios", que demonstravam a completa dependência da assistência na Bahia às ações da Santa Casa de Misericórdia; e "estabelecimentos e associações filantrópicas e beneficentes". Nessa última classificação, Vianna apontava que as instituições filantrópicas possuíam alguma intermediação do catolicismo, como ocorria com a Casa da Providência e a Associação das Senhoras da Caridade, que se destinava ao socorro de pobres e órfãs desvalidas, a Casa Pia e Colégio dos Órfãos de São Joaquim, e o Colégio dos Órfãos do Santíssimo Coração de Jesus.

O outro grupo, das instituições definidas como beneficentes, era composto por organizações classistas e étnicas. Entre elas, é possível destacar as instituições de colônia estrangeira, como portuguesas, espanholas, italianas, alemãs e francesas, que foram criadas com o objetivo de atender seus compatriotas, a exemplo da Deutscher Hilfsverein, para amparar alemães pobres, e a Société Française de Bienfaisance, que protegia os franceses. Mas foram a Sociedade Espanhola de Beneficência e a Real Sociedade Portuguesa de Beneficência Dezesseis de Setembro que conseguiram atingir o ponto máximo da organização de auxílio mútuo, a abertura de hospitais: o Hospital Português, em 1866, e o Hospital Espanhol, em 1925 (Souza, Sanglard, 2011, p.45).

A partir da compreensão do modelo liberal que caracterizava a sociedade brasileira ao longo do Império e da Primeira República e que se encontrava presente na Bahia, é possível identificar uma rede assistencial composta por variadas instituições, algumas delas criadas para atender os indivíduos nascidos em território nacional, outras para atender às necessidades de homens e mulheres oriundos de outros países.

O Grace Memorial Hospital, embora tenha surgido com o intuito de assistir e realizar trabalho de evangelização à população da cidade de Wagner, prestou atendimento a pacientes que vinham de outras localidades da Chapada Diamantina. 


\section{A Missão Presbiteriana norte-americana no Brasil e o Grace Memorial Hospital}

A presença dos presbiterianos no Brasil está relacionada ao trabalho desenvolvido pelo Board of Foreign Missions. A instituição teve origem em um contexto social marcado pela disseminação do sentimento religioso. Em estudo sobre atividades de missionários norte-americanos no Oriente Médio, Mehmet Ali Dogan (2013) faz uma retrospectiva do processo que deu origem às primeiras missões protestantes. Elas estão relacionadas ao "Segundo grande despertar", uma série de reavivamentos evangélicos que sucederam o "Primeiro grande despertar", ocorrido entre 1730 e 1740 (p.19). O "Segundo grande despertar" foi um evento que impulsionou a participação de igrejas em todo o país, sendo que todas as denominações como os congregacionistas na Nova Inglaterra, presbiterianos na região do Atlântico central e metodistas e batistas no sudoeste tiveram participação (p.20).

Com o aumento dos discursos cristãos americanos sobre a criação de uma república piedosa, estimulou-se uma onda de ativismo social que levou à fundação de várias sociedades benevolentes e organizações missionárias como o American Board of Comissionaries for Foreign Missions (1810), a Home and Foreign Mission Society (1812), a General Missionary Convention of the Baptist Denomination in the United States for Foreign Missions (1814), a American Education Society (1815), a American Bible Society (1816), entre outras (Dogan, 2013, p.20-21).

A reunião ocorrida no dia 7 de junho de 1837, na Primeira Igreja Presbiteriana da cidade de Baltimore, criou o Board of Foreign Missions of the Presbyterian Church in the United States of America, que ficaria sob a supervisão e condução da Assembleia Geral. Além disso, deveria anualmente apresentar um relatório de seus trabalhos, além das medidas e planos que fossem considerados úteis e necessários, para serem aprovados (Presbyterian Church..., 1838, p.3). O objetivo do Board era difundir o Evangelho "a qualquer parte do mundo pagão e anticristão", sob a crença de que a "providência de Deus" poderia capacitar a sociedade a estender seus esforços evangélicos (p.3-5). Em 1 de novembro de 1837, meses após ter sido criada, a Presbyterian Foreign Missionary Society já tinha sob seu cuidado missionários e estações no norte da Índia (quatro postos), em Esmirna (esta não estava em funcionamento), na China, na África Ocidental e nas Índias Ocidentais (p.9-10).

De 1837 até aproximadamente 1862, o Board funcionou como uma sociedade caritativa da Igreja presbiteriana, sem status legal, sendo então incorporado pelo estado de Nova York. Em função da Guerra Civil, com a beligerância entre o norte e o sul dos EUA, a Igreja presbiteriana sofreu um cisma, dividindo-se em duas em 1861. A Igreja dos estados do norte, que posteriormente criou o Grace Memorial Hospital no Brasil, passou a se chamar Presbyterian Church of the United States of America (PCUSA), e a dos estados do sul se tornou The Presbyterian Church in the United States (PCUS). Elas divergiam em relação às práticas cotidianas de condução da Igreja e, principalmente, em relação à escravidão (Atique, 2007, p.141).

A Igreja do norte possuía estrutura administrativa independente em relação à do sul. O pastor Ashbel Green Simoton, natural da Pensilvânia, foi enviado ao Brasil em 1859 pelo Board of Foreign Mission, também chamado de Board of New York. Cerca de uma década 
depois chegaram os missionários George Nash Morton e Edward Lane, pelo Committee of Nashville, do sul (Atique, 2007). O presbiterianismo no Brasil reproduziu, mesmo que por alguns anos apenas, a divisão dos presbiterianos dos EUA.

Fernando Atique (2007, p.140) destaca a disseminação dos protestantes no país não só como "mensageiros da salvação cristã", mas como disseminadores do "mundo americano" e de seus símbolos. A educação teria destaque no referido projeto. $\mathrm{O}$ autor afirma que entre 1876 e 1975 foram construídas diversas "escolas americanas" no território nacional, que buscavam disseminar métodos e técnicas de ensino nos moldes dos praticados nos EUA. Elas foram consequência das missões protestantes que chegaram ao Brasil na segunda metade do século XIX. Os estrangeiros aliaram a formação de escolas à constituição de suas denominações religiosas, ora como modo de promover a aproximação entre os missionários e a população a ser evangelizada, ora como forma de garantir acesso pleno dos povos praticantes da fé reformada à leitura e à interpretação da Bíblia, consideradas condições básicas do protestantismo (Atique, 2007, p.135).

Silas de Souza (2011, p.177-222), em estudo sobre o presbiterianismo, refere-se ao grande investimento em educação empreendido por esses religiosos, em diversas partes do mundo. Embora a origem da Igreja presbiteriana deva ser buscada no período da Reforma Protestante do século XVI, ligada ao pensamento do reformador João Calvino, no Brasil o presbiterianismo só se estabeleceu no século XIX. No estado da Bahia, assim como no Brasil, a população era majoritariamente católica. Em 1890, havia 99,90\% católicos e 0,09\% protestantes. Em 1900, esses números corresponderam a 97,41\% e 0,14\%, respectivamente. Em 1940, 98,91\% dos habitantes informaram ser católicos e 0,78\% disseram ser protestantes. Para 1950, o recenseamento revelou 98,04\% de católicos e 1,15\% de protestantes. Não há informações relativas a 1920 (IBGE, 1955).

Esses dados devem ser vistos com reserva, porque muitos praticantes de outras religiões poderiam afirmar ser católicos, pois somente com a Constituição de 1891 foi assegurada no país a liberdade de indivíduos e confissões religiosas para exercer o seu culto (Brasil, 1891). Os protestantes representavam uma pequena parcela da população, e o investimento, inicialmente em educação e posteriormente na saúde, foi uma forma de tentar aumentar o número de fiéis. Segundo Lyndon Santos (2010, p.109), os protestantes aproveitaram os espaços que foram deixados pelo fim do culto oficial e intensificaram as ações evangelizadoras da população. Ampliaram suas instituições, como escolas, seminários, hospitais, sociedades bíblicas, editoras e publicações. Para o autor, estratos mais baixos e médios acolheram a fé protestante com sua ênfase na salvação, na Bíblia e na simplicidade do ritual de culto. As conversões aconteciam via uma mensagem que objetivava a mudança da moral e dos costumes e a apropriação de outro modo de experimentar o sagrado, em contraste com as práticas católicas, africanas e indígenas (Santos, 2010, p.109).

Os missionários da Missão Presbiteriana norte-americana no Brasil eram oriundos de diversos lugares, como Ohio, Pensilvânia, Indiana, Nova Zelândia, Inglaterra e Escócia. Formada por pastores, professores, engenheiros agrônomos, médicos, enfermeiras, aviadores, entre outros, propunham a missão de "salvar a alma e o corpo dos homens e mulheres" do "Brasil tropical", expressão utilizada por eles para se referir ao interior brasileiro (Nascimento, 2005, p.1). 
Em 1896, a Missão do Brasil se dividiu, territorialmente, em Missão Sul do Brasil, que compreendia os estados de São Paulo, Rio de Janeiro, Paraná e Santa Catarina, e Missão Central do Brasil, com Bahia, Sergipe, Goiás, Mato Grosso e norte de Minas Gerais. Pelas dificuldades de comunicação e transporte no território baiano, as instituições organizadas nos três últimos estados foram transferidas para a Missão Sul do Brasil (Nascimento, 2005, p.9).

Tiago Ferreira dos Santos (2017) afirma que a atuação na esfera da saúde, de forma mais sistemática, foi uma inovação para a Missão Central do Brasil. A expansão da atuação para áreas que não eram características deveu-se à necessidade e à possibilidade de alcance de mais pessoas pela mensagem presbiteriana. A veiculação de um trabalho médico relacionado à estratégia missionária e vinculado à ajuda humanitária era algo previsto nas ações evangelísticas das missões e, dessa forma, definia-se como objetivo "manifestar o espírito de Cristo, através da prevenção e cura de doenças para que os homens" aceitassem "a Cristo como mestre e Salvador de suas vidas" (Santos, 2017, p.159). A ação presbiteriana na região de Ponte Nova e em outras localidades do Brasil fez parte do projeto "civilizador" para o interior do país, montado a partir de três eixos: religião, educação e saúde (Nascimento, 2005, p.6).

No que diz respeito à atuação do médico Walter Wood, em Ponte Nova, após sua chegada em 1916, ele precisou revalidar o diploma na Faculdade de Medicina da Bahia, tendo que se deslocar para Salvador, durante parte de 1917 e 1918, para cumprir um requisito legal ao exercício profissional em terras brasileiras. Seu nome aparece, em 1919, na relação dos formados da Faculdade de Medicina da Bahia (Fameb, s.d.; Santos, 2017, p.165-166). Em Ponte Nova, a assistência à saúde prestada pelo doutor Wood foi iniciada em uma sala do colégio local. O crescimento do número de pacientes que procuravam tratamento levou à necessidade de obter um espaço específico.

A primeira unidade foi uma pequena casa de três quartos, onde funcionava a sala de cirurgia e as enfermarias de homens e mulheres. Os instrumentos eram esterilizados num forno de barro de assar pão, fora da casa. Nas palavras de Janet Graham de Araújo (2008, p.1), profissional que assumiu a direção da Escola de Auxiliares de Enfermagem de Ponte Nova, em 1961, apesar de Ponte Nova ser composta por pouco mais de uma dúzia de casas, em 1917, foram atendidos 4.862 pacientes que vinham das mais diversas cidades da região, percorrendo longas distâncias a pé, a cavalo ou transportados em redes. Em 1921, esse número chegou a 9.196. O crescimento dos atendimentos clínicos e cirúrgicos levou à discussão sobre a importância da criação de uma unidade hospitalar.

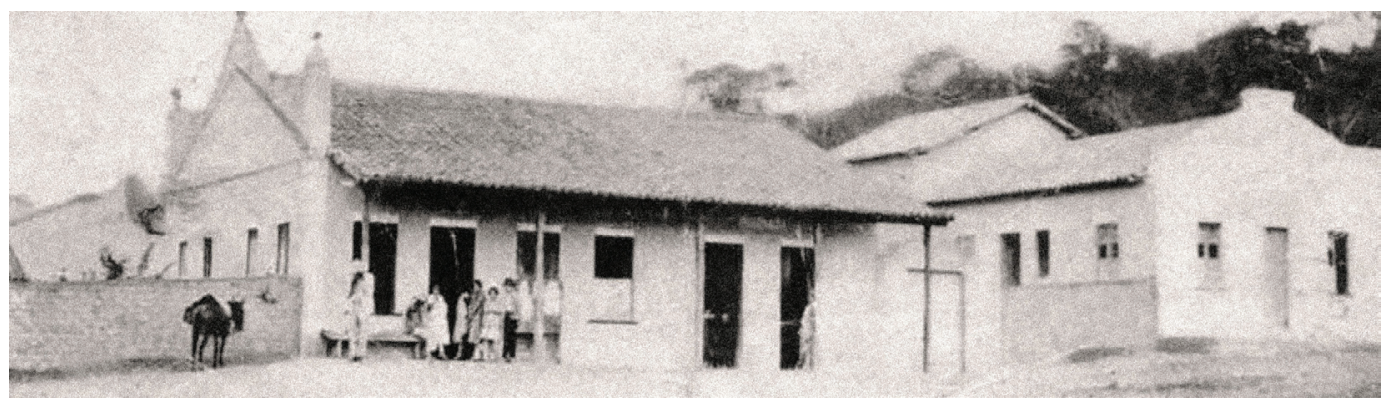

Figura 1: Grace Memorial Hospital e Clínica, Wagner (BA), década de 1920 (Nascimento, 2005, p.80) 
Inicialmente havia 25 leitos, ampliados, em seguida, para trinta, distribuídos em duas enfermarias e cinco quartos particulares. Mesmo nesse momento, já eram realizadas cirurgias, conforme se pode observar, além da defesa de que a cura estava associada à conversão à religião:

O ano passado foi duro, Dr. Wood tratou nada menos que 9.196 pacientes. Alguns dos cegos com catarata veem, alguns dos coxos e aleijados são capazes de andar; uma vida aqui e ali foi salva; mas talvez, acima de tudo, um grande número tenha sido aliviado do sofrimento, tenha ouvido a pregação do Evangelho e formado novas ideias sobre o que estamos tentando fazer por eles. Um caso ilustrará. Um homem com gangrena do pé, que foi visto no retorno do Dr. Wood do último Encontro da Missão, chegou a Ponte Nova em uma maca no último mês de dezembro. A perna foi amputada, mas por causa da condição fraca a cicatrização da ferida foi atrasada. Quando cheguei ao homem era um católico fervoroso. Um dia perguntei onde a perna amputada estava enterrada, porque, se estivesse no cemitério protestante, sua perna, sendo católica, não poderia curar. Outra operação foi necessária para fechar a ferida, e depois de três meses, quando ele voltou para casa a cavalo, ele carregava uma Bíblia e alguns folhetos consigo (Presbyterian Church..., 1922, p.310).

Os anos 1921 e 1922 foram difíceis na vida de Wood, que havia perdido a esposa (Santos, 2017, p.171). No relatório anual do Board of Foreign Missions de 1922, afirmava-se que a missionária Grace Wood havia sido preparada para o trabalho no Brasil na Lohriville High School e no Huron College, sendo sua morte, em 18 de junho de 1921, um grande golpe para o trabalho que desenvolvia. Ela faria falta para todos que com ela conviveram. Segundo o relatório: "Os membros da missão perderam uma amiga, o trabalho da missão uma valiosa ajudante e o povo brasileiro aquela que se dedicou às suas necessidades" (Presbyterian Church..., 1922, p.70).

Após esse acontecimento, Wood obteve licença para se especializar em medicina tropical, em Londres. A missão se preocupou com a continuidade do trabalho desenvolvido, pois ele estava ambientado ao local e havia criado uma imagem que o qualificava e atraía muitas pessoas. Consideravam uma calamidade para o projeto de Ponte Nova a sua desistência. Dessa forma, ofereceram-lhe como condição de trabalho autonomia para captar recursos, como forma de mantê-lo no local. Ele experimentou inicialmente o exercício da medicina independente, mas logo retornou à vinculação institucional da missão (Santos, 2017, p.172).

O Grace Memorial Hospital tinha caráter confessional declarado. Contudo, era pautado no liberalismo e no processo de aceitação pessoal. Atendia a todos sem distinção religiosa, econômica ou social. O seu objetivo não era só "curar o corpo", mas também "salvar a alma". Eram celebrados cultos ao longo do dia, e a Bíblia sempre estava disponível às pessoas que por lá transitavam (Santos, 2017, p.177-178).

Com o acordo firmado entre o governo da Bahia e o Departamento Nacional de Saúde Pública (DNSP), em 15 de abril de 1921, para a realização de serviços de profilaxia rural, de combate à sífilis e às doenças venéreas, de luta contra a tuberculose e de higiene infantil (Batista, 2017, p.30, 71), e com o advento da Subsecretaria de Saúde e Assistência Pública e do Código Sanitário, muitas ações sanitárias foram desenvolvidas no combate a doenças endêmicas, como a tuberculose, na Bahia (Silva, 2018). Na região da Chapada Diamantina 
não houve a criação de instituições de assistência à saúde a partir do referido acordo. Os postos de saneamento rural foram instalados em localidades onde havia hospitais das Santas Casas de Misericórdia, o que reforçava a estrutura de assistência nesses lugares. Em outros espaços, nos quais não havia instituições, foram enviadas expedições para realizar investigações epidemiológicas e tentar erradicar epidemias. Entre 5 de março e 27 de dezembro de 1926, 44 expedições partiram para variados municípios. Entre 1927 e 1928, mais 66 viagens foram realizadas por médicos, para tentar suprir a lacuna da assistência à saúde nos territórios desprovidos de postos de saneamento rural e, ao mesmo tempo, mapear as condições sanitárias dos sertões da Bahia (Batista, 2017, p.229).

No relatório de 1925, da expedição para analisar o surto de febre de "mau caráter" no município de Palmeiras, próximo a Ponte Nova, o doutor Exupério Braga (1925, p.3) afirmou que Walter Wood esteve ali anteriormente, e que "pelo resultado do exame bacteriológico realizado pelo Dr. Wood, médico americano e pastor protestante, com casa de Saúde em Ponte Nova, acreditamos ter havido peste bubônica, ponto este situado a 4 léguas desta vila". O reconhecimento do diagnóstico anterior, por parte do doutor Braga, revela como Wood desempenhava ações sanitárias na região antes mesmo do Grace Memorial Hospital ter sido inaugurado e sugere que a ausência de instituições filantrópicas e de instituições de saúde estatais pode ter contribuído para que a Missão Central Presbiteriana achasse conveniente a fundação de um hospital naquela região.

Em 1954, o médico Walter Wood, ao completar 70 anos, aposentou-se e retornou aos EUA, onde continuou trabalhando até sua morte, em 1962. Alguns médicos deram continuidade ao seu trabalho no hospital, permanecendo por meses ou anos na cidade. Mas foi em 1959 que o médico Jonas de Araújo, recém-formado, foi trabalhar no Grace Memorial, tornando-se cirurgião e clínico. Nas palavras de Janet de Araújo (2008), ele atendia pacientes portadores das mais variadas doenças e fazia cirurgias de fígado, baço, estômago, rins, além das cirurgias ginecológicas e cesarianas. Também cuidava dos olhos, garganta, nariz e ouvido. Tratava com sucesso de fraturas e atendia todo tipo de emergência. Era, portanto, "um verdadeiro médico" (Araújo, 2008, p.6). Cerca de $85 \%$ a 90\% dos atendimentos eram gratuitos. Nessa época, ainda não havia luz elétrica, levando o hospital a funcionar com motor a diesel das 16 às 22 horas. A água era bombeada do rio Utinga para um tanque subterrâneo, morro acima, de onde descia por gravidade. $\mathrm{O}$ abastecimento de alimentos que não eram encontrados na região era feito por encomenda a Salvador, vindo de caminhão. Assim também chegavam os materiais médicos, equipamentos e medicamentos (p.6). Compreende-se que, durante toda a sua história, o Grace Memorial Hospital desempenhou um papel importante na assistência à saúde na Chapada Diamantina, complementar à ação do Estado.

Em 1971, a missão presbiteriana suspendeu o trabalho no Brasil. Nem a prefeitura de Wagner, nem o governo do estado se interessaram em manter o hospital em funcionamento, o que levou ao seu fechamento. O médico Jonas Araújo continuou atendendo de forma autônoma na região, e em 1976 comprou a propriedade e os prédios vazios do Grace Memorial. A reabertura do hospital, no entanto, só ocorreu em 1985 e, mesmo assim, seu funcionamento sempre ocorreu com dificuldades. Essas foram agravadas em 2007, com a morte de Jonas Araújo. O hospital passou a funcionar sem médico, oferecendo apenas atendimentos paramédicos e de serviço social, posteriormente encerrando suas atividades. 


\section{O acervo do Grace Memorial}

O acervo do Grace Memorial Hospital foi doado à Universidade do Estado da Bahia (Uneb), campus II, Alagoinhas, em 4 de abril de 2012, e é composto por prontuários médicos e fichas de pacientes atendidos de 1955 a 1971. Dos 2.699 prontuários organizados, há 1.544 $(57,2 \%)$ do sexo feminino e $1.155(42,8 \%)$ do sexo masculino.

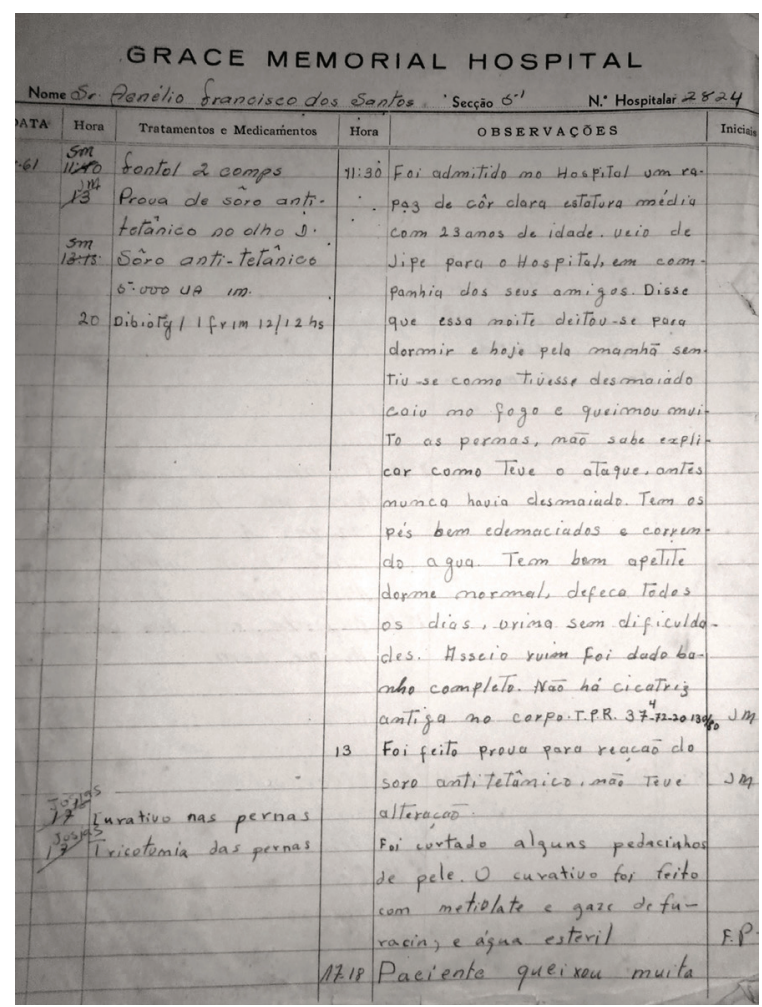

Figura 2: Prontuário médico (Acervo do Grace Memorial Hospital)

Os prontuários médicos são fontes importantes para acompanhar o processo de internamento e evolução dos pacientes. Aqueles que eram admitidos no Grace Memorial Hospital tinham seus registros efetuados em detalhes pelo médico e por enfermeiras. Cada prontuário, além de possuir um número específico e informar o nome completo do paciente, tinha espaços para a anotação da data, da hora, do tratamento e dos medicamentos ministrados. Além desses campos, havia o direcionado às observações gerais e o que deveria ser preenchido com as iniciais dos profissionais que faziam o atendimento. Esses dados eram atualizados algumas vezes ao dia, à medida que fossem realizados os procedimentos. As informações mais detalhadas ficavam registradas nas observações. Nelas eram descritas as condições de admissão dos doentes, sua cor, idade, estatura, além da forma como chegaram ao hospital e o motivo da internação. É possível observar ainda, em alguns prontuários, comentários sobre o estado emocional dos doentes e suas reações aos tratamentos sugeridos. Os prontuários, após serem colocados em envelopes individuais, com a numeração específica e o nome do doente, eram arquivados. 
Essa documentação, após ter sido recebida pela Uneb, passou por um processo de higienização, ocasião em que foram separados os prontuários que estavam em bom estado de preservação, os considerados em estado razoável de conservação e os muito danificados.

Nas fichas de atendimento, as informações dos pacientes eram mais resumidas, embora possuíssem também espaços para o registro de nome, endereço, profissão, idade, sexo, queixa principal, diagnóstico e lista de procedimentos que foram realizados. Essa forma de registro ocorria no serviço ambulatorial. Caso houvesse necessidade, o doente era encaminhado para o internamento, gerando a abertura do prontuário. Atualmente esse material está sendo digitalizado.

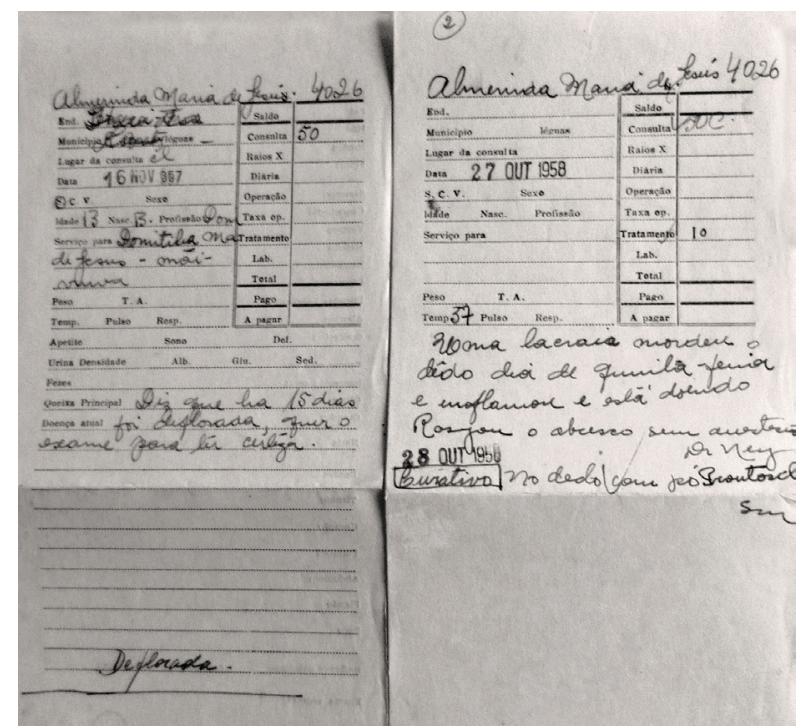

Figura 3: Fichas de pacientes atendidos (Acervo do Grace Memorial Hospital)

O acervo do Grace Memorial Hospital é rico em informações ainda não exploradas e pode auxiliar na compreensão das instituições que desempenharam assistência à saúde na atual região de Wagner, das formas de tratar a população doente e, especialmente, do papel desempenhado por instituições internacionais no desenvolvimento da saúde no Brasil, nas suas interfaces com aspectos relacionados à religião e à atuação de médicos e enfermeiras.

\section{REFERÊNCIAS}

ARAÚJO, Janet Graham de.

Grace Memorial Hospital: 92 anos salvando vidas. Wagner: [s.n.]. 2008.

ATIQUE, Fernando.

Arquitetando a "boa vizinhança": a sociedade urbana do Brasil e a recepção do mundo norteamericano, 1876-1945. Tese (Doutorado em História e Fundamentos Sociais da Arquitetura e do Urbanismo) - Universidade de São Paulo, São Paulo. 2007.
BARRETO, Maria Renilda Nery.

A Santa Casa de Misericórdia da Bahia e a assistência aos doentes no século XIX. In: Souza, Christiane Maria Cruz de; Barreto, Maria Renilda Nery (Org.). História da saúde na Bahia: instituições e patrimônio arquitetônico, 18081958. Barueri: Minha Editora. p.2-26. 2011.

BATISTA, Ricardo dos Santos.

Assistência à saúde no Hospital Santa Izabel, 1900-1930. In: Silva, Maria Elisa Lemos Nunes 
da; Batista, Ricardo dos Santos. História e saúde: políticas, assistência, doenças e instituições na Bahia. Salvador: Eduneb. p.49-68. 2018.

BATISTA, Ricardo dos Santos.

Sífilis e reforma da saúde na Bahia, 1920-1945.

Salvador: Eduneb. 2017.

BRAGA, Exupério da Silva.

Relatório sobre o combate a febre de mau caráter no município de Palmeiras. Fundo Secretaria de Saúde, grupo Gabinete do Secretário, caixa 4028, maço 17 (Arquivo Público do Estado da Bahia, Salvador). 1925.

BRASIL.

Constituição de 1891. Disponível em: <http://www2.camara.leg.br/legin/fed/ consti/1824-1899/constituicao-35081-24fevereiro-1891-532699-publicacaooriginal-15017pl.html>. Acesso em: 24 jul. 2018. 1891.

CASTEL, Robert.

As metamorfoses da questão social: uma crônica do salário. Trad. Iraci D. Poleti. Petrópolis: Vozes. 2010.

DOGAN, Mehmet Ali.

American Board of Comissioners for Foreign Missions (ABCFM) and "Nominal Christians": Elias Riggs (1810-1901) and American missionary activities in the Ottoman Empire. Dissertation (Doctorate Degree in Philosophy) - The University of Utah, Salt Lake City. 2013.

FAMEB.

Faculdade de Medicina da Bahia. Relação dos formados em medicina pela Faculdade de Medicina da Bahia, 1812 a 2008. Disponível em: <http://www.fameb.ufba.br/dmdocuments/ formadosfmb1812a2007.pdf $>$. Acesso em: 23 jul. 2018. s.d.

IBGE.

Instituto Brasileiro de Geografia e Estatística. Conselho Nacional de Estatística e Recenseamento. Censo demográfico do estado da Bahia. Rio de Janeiro: IBGE (Série Regional, v.20, t.1). Disponível em: <https://ia802502.us.archive.org/6/items/ censo1950vol20t1ba/censo1950vol20t1ba.pdf $>$. Acesso em: 24 set. 2019. 1955.

NASCIMENTO, Ester Fraga Vilas-Boas Carvalho do.

Educar, curar, salvar: uma ilha de civilização no Brasil tropical. Tese (Doutorado em História da Educação) - Pontifícia Universidade Católica de São Paulo, São Paulo, 2005.

PRESBYTERIAN CHURCH...

Presbyterian Church in the USA. Annual report of the Foreign Missions of the Presbyterian Church, in the United States of America. New York: Scatcheed and Adams. 1838.

PRESBYTERIAN CHURCH...

Presbyterian Church in the USA. Annual report of the Foreign Missions of the Presbyterian Church, in the United States of America. New York: [s.n.]. 1922.

RUSSEL-WOOD, Anthony John R. Fidalgos e filantropos: a Santa Casa da Misericórdia da Bahia, 1550-1755. Brasília: Editora da UnB. 1981.

SANGLARD, Gisele; FERREIRA, Luiz Otávio. Caridade e filantropia: elites, estado e assistência à saúde no Brasil. In: Teixeira, Luiz Antônio; Pimenta, Tânia Salgado; Hochman, Giberto (Org.). História da saúde no Brasil. São Paulo: Hucitec. p.145-181. 2018.

SANTOS, Lyndon de Araújo.

O protestantismo no advento da República no Brasil: discursos, estratégias e conflitos. Revista Brasileira de História das Religiões, ano 3, n.8, p.103-120. Disponível em: <http://www.dhi. uem.br/gtreligiao/pdf7/07.pdf $>$. Acesso em: 6 nov. 2018. 2010.

SANTOS, Tiago Ferreira dos.

"Um banho de civilização no coração geográfico da Bahia": a ação missionária presbiteriana em Ponte Nova, 1906-1938. Dissertação (Mestrado em História) - Universidade Federal da Bahia, Salvador. 2017.

SILVA, Maria Elisa Lemos Nunes da.

O dispensário Ramiro de Azevedo e a constituição de políticas de enfrentamento da tuberculose na Bahia na década de 1920. In: Silva, Maria Elisa Lemos Nunes da; Batista, Ricardo dos Santos. História e saúde: políticas, assistência, doenças e instituições na Bahia. Salvador: Eduneb. p.69-102. 2018.

SOUZA, Christiane Maria Souza de; SANGLARD, Gisele.

Saúde pública e assistência na Bahia da Primeira República, 1889-1929. In: Souza, Christiane Maria Souza de; Sanglard, Gisele (Org.). História da saúde na Bahia: instituições e patrimônio arquitetônico, 1808-1958. Barueri: Editora Fiocruz; Manole. p.27-73. 2011.

SOUZA, Silas de.

Presbiterianismo no Brasil. In: Silva, Elizete et al. (Org.). "Fiel é a palavra": leituras históricas dos evangélicos protestantes no Brasil. Feira de Santana: Uefs Editora. p.177-222. 2011. 